\title{
Enhanced uptake of water by oxidatively processed oleic acid
}

\author{
A. Asad, B. T. Mmereki, and D. J. Donaldson \\ Department of Chemistry and Department of Physical and Environmental Sciences, University of Toronto, 80 St. George St., \\ Toronto, Ont. M5S 3H6, Canada
}

Received: 2 July 2004 - Published in Atmos. Chem. Phys. Discuss.: 29 July 2004

Revised: 13 October 2004 - Accepted: 14 October 2004 - Published: 19 October 2004

\begin{abstract}
A quartz crystal microbalance apparatus has been used to measure the room temperature uptake of water vapour by thin films of oleic acid as a function of relative humidity, both before and following exposure of the films to various partial pressures of gas phase ozone. A rapid increase in the water-sorbing ability of the film is observed as its exposure to ozone is increased, followed by a plateau region in which additional water is taken up more gradually. In this fully-processed region the mass of water taken up by the film is about 4 times that of the unprocessed film. Infrared spectra of the films, measured after variable exposures to ozone, show dramatic increases in both the "free" and hydrogenbonded $\mathrm{O}-\mathrm{H}$ stretching regions, and a decrease in the intensity of olefinic features. These results are consistent with the formation of an oxygenated polymeric product or products, as well as the gas phase products previously identified.
\end{abstract}

\section{Introduction}

The oxidizing nature of Earth's atmosphere has the result that, over time, chemical transformations will oxidize any reduced species exposed to the atmosphere. Such oxidative processes are not just important to chemical compounds in the gas phase, but also those associated with condensed phases, either solid or liquid. For example, the oxidation of $\mathrm{SO}_{2}$ to sulfuric acid in water droplets is generally more important than the corresponding gas phase process (FinlaysonPitts and Pitts, 2000).

Recently there has been a surge of interest in the oxidation of organic films and particles by atmospheric oxidants, primarily ozone and $\mathrm{OH}$. This has been motivated by field measurements which find organics to be ubiquitous components of atmsopheric aerosol particles, with dry mass fractions typ-

Correspondence to: D. J. Donaldson

(jdonalds@chem.utoronto.ca) ically 10-50\% (Matsumoto et al., 1997; Middlebrook et al., 1998; Murphy et al., 1998a, b; Novakov et al., 1997a, b; Novakov and Penner, 1993). Since atmsopheric aerosols exert an as-yet unquantified indirect effect on climate forcing, through their ability to condense water and thus form cloud droplets (their cloud condensation nucleating - $\mathrm{CCN}$ - ability), understanding how atmospheric oxidation of organic particles, or of the organic outer layers on particles, (Ellison et al., 1999) affects CCN abilities is of great importance. Consequently, numerous recent studies have examined the rates of oxidative processing of various proxies for organic-containing particles. A recent review by Rudich (2003) provides an excellent survey of the literature through early 2003.

Recent attention has been given to ozone uptake by organic liquids (de Gouw et al., 1998; Eliason et al., 2003) and the oxidation of films and aerosols composed of biogenic fatty acids (Morris et al., 2002; Smith et al., 2002; Moise and Rudich, 2003; Thornberry and Abbatt, 2004; Katrib et al., 2004). Such long chain carboxylic acids are often found to be significant components of atmospheric particles (Schauer, et al., 1996). They contain one or more carboncarbon double bonds, which are susceptible to oxidative attack by all of the important atmospheric oxidants $\left(\mathrm{OH}, \mathrm{O}_{3}\right.$, $\mathrm{NO}_{3}, \mathrm{Cl}$, etc.). Reactive uptake coefficients on the order of $10^{-3}$ are found for gas phase ozone interacting with oleic acid (9-octadecenoic acid), linoleic acid (9,10-nonadec-dienoic acid) and linolenic acid (5,8,11-eicos-trien-oic acid). Heterogeneous reaction rates with $\mathrm{OH}$ seem to be even faster, with reactive uptake coefficients $>0.1$ (Bertram et al., 2001). The nature of the products formed in such ozone + olefin reactions depends upon the oxidant, but in all cases, there seems to be an increase in the oxygen content of the remaining condensed phase material (Eliason et al., 2003, 2004; Katrib et al., 2004). 
An increase in the oxidation state (or in the oxygen:carbon ratio) of the components of a film or particle is expected to give an increase in its hygroscopicity (Saxena and Hildemann, 1997; Hemming and Seinfeld, 2001; Demou et al., 2003). Contact angle (Thomas et al., 2001) and microbalance (Rudich et al., 2000; Demou et al., 2003) studies using films and self-assembled monolayers have shown that this is, in fact, the case. Very recent work has indicated that an increase in $\mathrm{CCN}$ ability of oleic acid aerosols results from exposure to ozone (Broekhuizen et al., 2004). The present work reports on our study of the increasing water uptake potential of oleic acid films as a function of their exposure to ozone. We report results from quartz crystal microbalance experiments which show that the amount of water sorbed by oleic acid can increase up to a factor of 4 upon oxidative processing. Infrared spectra of the processed film show extensive "new" bands in the $\mathrm{OH}$ stretching region.

\section{Experimental}

The water uptake measurements were conducted using a quartz crystal microbalance (QCM) apparatus in a manner almost identical to that described in Demou et al. (2003). A QCM consists of a piezoelectric oscillator whose resonant frequency depends sensitively upon the mass deposited onto the crystal face. For the deposition of thin, rigid films, the frequency change is a linear function of the mass deposited, as expressed by the Sauerbrey equation: $\Delta m=C \Delta f$, where $\Delta m$ is the deposited mass, $\Delta f$ is the change in frequency, and $C$ is a constant of proportionality. The validity of this simple expression for applications such as the present one has been explored (Tsionsky and Gileadi, 1994; Rodahl and Kasemo, 1996). Our experience with our instrument suggest that the Sauerbrey equation may safely be used in the present experiments, as well. The sensitivity to mass changes was calibrated by depositing known amounts of water onto the crystal and monitoring the frequency change. The calculated and measured frequency changes agreed to within $1 \%$. This assumption was further verified by using the value of $\Delta f$ to calculate the mass of film compound present on the crystal, and checking this value against that estimated from the amount of film material deposited. Typically, the two mass estimates agreed to within $20 \%$.

The QCM used gold coated quartz crystals, 0.550 inches in diameter with fundamental frequency $6 \mathrm{MHz}$ and a sensitivity parameter of $8.147 \times 10^{7} \mathrm{~Hz} \mathrm{~cm}^{2} \mathrm{~g}^{-1}$. It was held in a temperature controlled mount suspended in the centre of the $5.1 \mathrm{~L}$ experimental chamber, with its horizontal crystal surface facing upwards. For these experiments, the relative humidity in the chamber was ramped up or down by varying the flow rates of two streams of nitrogen, one of which passed through a water bubbler and the other which did not. Wet and dry flows of nitrogen combined in a mixing vessel, then flowed through the chamber at a total rate of approxi- mately $1.0 \mathrm{~L} \mathrm{~min}^{-1}$. The relative humidity and temperature were monitored using a commercial hygrometer mounted directly above the QCM crystal. Our earlier calibration measurements, using saturated salt solutions, suggest a hygrometer accuracy of approximately $+5 \%$ RH between 10 and $90 \%$ $\mathrm{RH}$, and precision of about $2 \%$. The chamber temperature was typically $20-22^{\circ} \mathrm{C}$.

Initially, oleic acid films were prepared by placing a few microliters of a $10 \% \mathrm{v} / \mathrm{v}$ methanol solution of the acid onto the crystal surface, then allowing it to evaporate under a dry nitrogen flow. As described in Demou et al. (2003), this procedure yields uniform films whose mass, as determined by the QCM, is within about $20 \%$ of that expected, given the amount of solution used. This film preparation method gave rise to water uptake behaviour which was unlike that observed for any other compounds studied to date (vide infra). A second film preparation method was then used, whereby neat oleic acid was spread on the crystal surface using a cotton swab. The films prepared this way had masses between 60 and $100 \mu \mathrm{g}$, as determined by the QCM frequency change only. This method did yield reproducible and physically reasonable water uptake measurements. The results reported here utilized that film preparation method.

Uptake experiments consisted of preparing the film as outlined above, decreasing the relative humidity (at $21-23^{\circ} \mathrm{C}$ ) to $<5 \%$ in the experimental chamber using a flow of dry nitrogen gas, then placing the coated crystal in its holder in the chamber. When the frequency output of the QCM stabilized, the relative humidity (RH) was increased by introducing a flow of humidified nitrogen into the chamber, raising the RH to near $100 \%$ over the course of about 40 min. After a few minutes at this RH, the flow of humidified nitrogen was switched for dry nitrogen, and the RH dropped to $<5 \%$, again over the course of some $40 \mathrm{~min}$. During the entire ramping up (and for a few runs, down) of the RH, both its value and the oscillation frequency of the crystal were monitored at one minute intervals.

Following such a cycle, the crystal was removed from the chamber and placed in a small Pyrex chamber through which either neat oxygen $(99.996 \%)$ or a mixture of oxygen and ozone was slowly flowed at 1 bar total pressure. Ozone could be generated in this stream using a variable ozone generator (Model 600-Jelight Company). The $\mathrm{O}_{3} / \mathrm{O}_{2}$ mixture flowed through Teflon tubing to the reaction zone, making photolytic production of $\mathrm{HO}_{\mathrm{x}}$ via ozone photolysis unlikely. Concentrations of ozone in the reaction flask could be varied over the range $10^{14}-10^{16}$ molecules $\mathrm{cm}^{-3}$, as determined separately by absorbance spectroscopy using the Hartley band absorption of ozone. The crystal was exposed to this flowing gas for a measured length of time, then replaced in the water uptake apparatus where an additional water uptake measurement was carried out. Typically, this measurement was repeated 2-3 times to determine the precision. The oscillation frequency measured at the lowest RH values remained constant from run to run, indicating that the mass of the film 
did not change through evaporation or reaction with water vapour.

This procedure was carried out using a range of ozone concentrations and exposure times. Generally, at least two separate experiments (using different films) were performed at each $\left\{\left[\mathrm{O}_{3}\right]\right.$, time $\}$ combination. For later experiments, the initial (pre-processing) water uptake run was eliminated, because the water uptake measurements on neat oleic acid were very reproducible (to within about $10 \%$ ).

Infrared spectra of unprocessed and processed films were measured using an FTIR microscope. Water uptake measurements were not performed on these films, which were not protected from the ambient conditions. Spectra were taken of films which had been exposed to various ozone concentrations for different times. The $\left\{\left[\mathrm{O}_{3}\right]\right.$, time $\}$ combinations chosen for these measurements matched several of those for which the water uptake was determined. Using the FTIR microscope, a spectral mapping of several areas on each of the films could be done. The crystal with the organic coating was placed on the microscope bench such that the same area could be mapped before and after the film was exposed to ozone. A survey of the spectral map from each area gave spectra for several locations within the map. These were very similar for each one of the films measured here, with some minor differences in relative intensities appearing at different locations within some films, but no large differences observed.

Oleic acid ( $99 \%)$ was purchased from Aldrich, kept in a darkened container in a refrigerator and used without purification. Nitrogen and oxygen (UHP) were used as delivered.

\section{Results}

\subsection{Water uptake by unprocessed oleic acid}

The amount of water sorbed by oleic acid films (prepared in two different ways, as described above) as a function of the ambient relative humidity is shown in Fig. 1a. The uptake is given in moles of water sorbed per mole of oleic acid present, to compare with our previous results using a suite of organic compounds, which are summarized in Fig. 1b. Two very different interactions with water vapour are apparent, depending on how the film is prepared. Experiments done using a film prepared using neat oleic acid show the uptake vs. relative humidity behaviour expected on the basis of our earlier work: a slow rise in the amount of water sorbed up to about $80 \%$ relative humidity, followed by a rapid increase at higher RH. As shown in Fig. 1b, this type of behaviour is fairly general, with the steepness of the rise dependent on the degree of oxidation (or O:C ratio) of the film compound. However, films prepared from a methanol solution of oleic acid give uptake curves which are unlike any others we have observed to date, showing a very rapid increase in sorbed water from the lowest $\mathrm{RH}$ values.
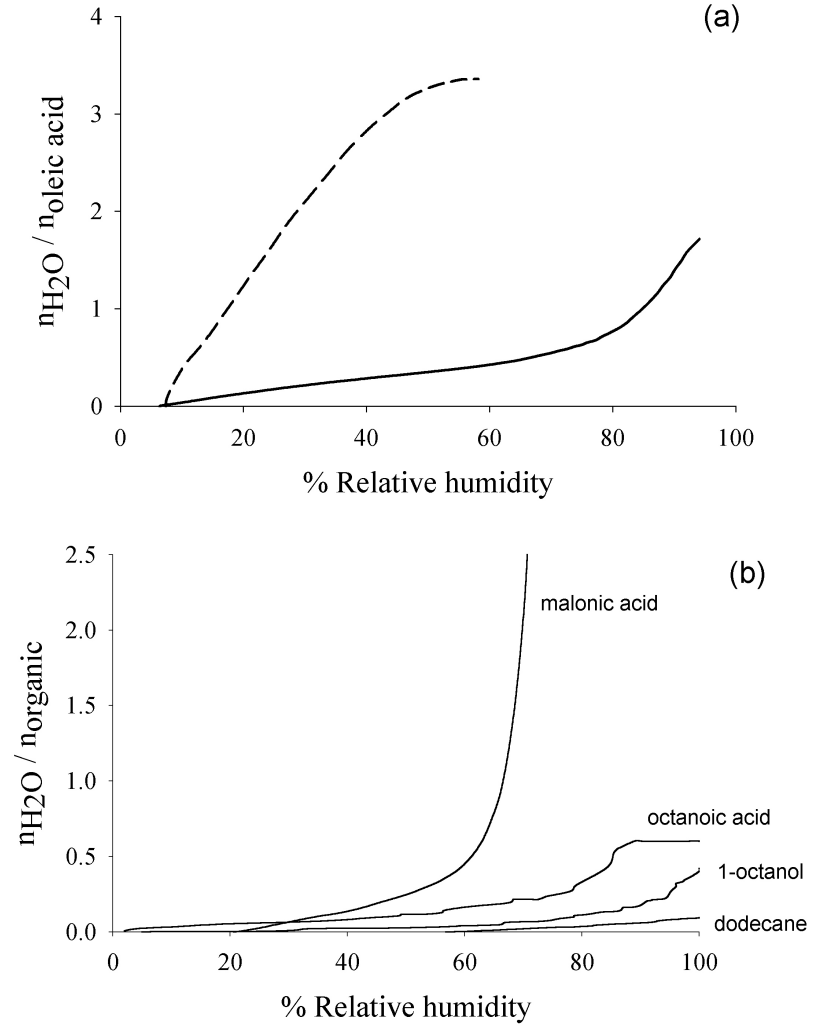

Fig. 1. (a) Uptake of water by oleic acid films as a function of the ambient relative humidity. Films formed from neat oleic acid give the result shown as the solid line; the dashed line shows the result obtained using films formed from methanol solutions of the acid. (b) Summary of our previous uptake results (Demou et al., 2003). The water-sorbing ability increases with the degree of oxidation (or $\mathrm{O}: \mathrm{C}$ ratio) of the compound.

This rapid increase, and the large number of water molecules (ie - up to 4) associated with each oleic acid at lower RH values, seem unphysical, given the chemical structure of oleic acid. The presence of a long $\left(\mathrm{C}_{17}\right)$ hydrophobic chain would suggest a weak water-sorbing ability for oleic acid, certainly different from that observed using malonic acid or propan-di-ol films, for example. The result from a neat oleic acid film is similar to that seen in octanoic acid films, with a maximum uptake near $100 \% \mathrm{RH}$ of a bit more than 1 water molecule per acid molecule. We take this result to represent the "true" uptake behaviour of oleic acid. We note as well that the use of methanol solutions of oleic acid to form aerosols gives strikingly different $\mathrm{CCN}$ activities from the use of neat oleic acid (Broekhuizen et al., 2004; vide infra). Our results also suggest changes in the interactions between water and oleic acid when a sample is formed through evaporation of a methanol solution. 


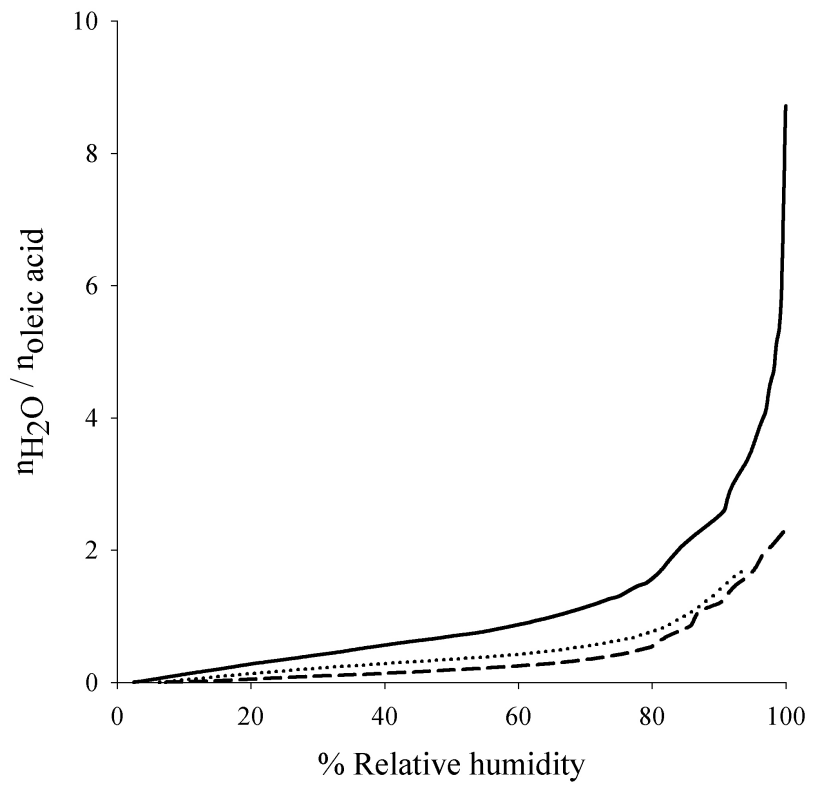

Fig. 2. Water uptake by oleic acid films which are: unprocessed (dotted line); exposed to 1 bar $\mathrm{O}_{2}$ for $60 \mathrm{~min}$ (dashed line); exposed to $270 \mathrm{ppm} \mathrm{O}_{3}$ in 1 bar $\mathrm{O}_{2}$ for 5 minutes (solid line).

\subsection{Water uptake following exposure to ozone}

Following a water uptake and release cycle (during which the RH was ramped up to $100 \%$, then back down to $<5 \%$ ) using a neat film, the crystal was removed and placed in a small chamber through which $1 \mathrm{~L} \mathrm{~min}^{-1}$ (at 1 bar pressure) of $\mathrm{O}_{2}$ was flowed. The crystal was exposed to this oxygen flow for 30-60 min, then replaced in the QCM apparatus and a water uptake curve was measured. Figure 2 shows that exposure to pure oxygen for up to one hour has no effect (within our error limits) on the water uptake behaviour. In addition, the mass of the film measured before and after exposure to $\mathrm{O}_{2}$ was identical, suggesting that no chemical changes occurred during exposure to oxygen.

The result is very different when the film is exposed to small amounts of ozone. Five minutes of exposure to ozone concentrations of less than $300 \mathrm{ppm}$ in 1 bar of oxygen gives a water uptake curve, also shown in Fig. 2, which indicates much increased hydrophilicity of the film. The relative increase in the amount of water taken up shown in Fig. 2 represents an absolute increase in the mass of water sorbed following processing. A small (as much as 5\%) mass increase is also measured in most, but not all, of the films exposed to ozone but prior to water exposure. Figure 3 a illustrates the increase in the maximum water uptake by plotting the moles of water sorbed (measured at $95 \% \mathrm{RH}$ ) per mole of oleic acid originally in the film, as a function of the exposure time to ozone for several ozone concentrations. A rapid increase is seen, followed by a plateau, where increasing the amount of exposure to ozone no longer increases the water uptake properties of the film.
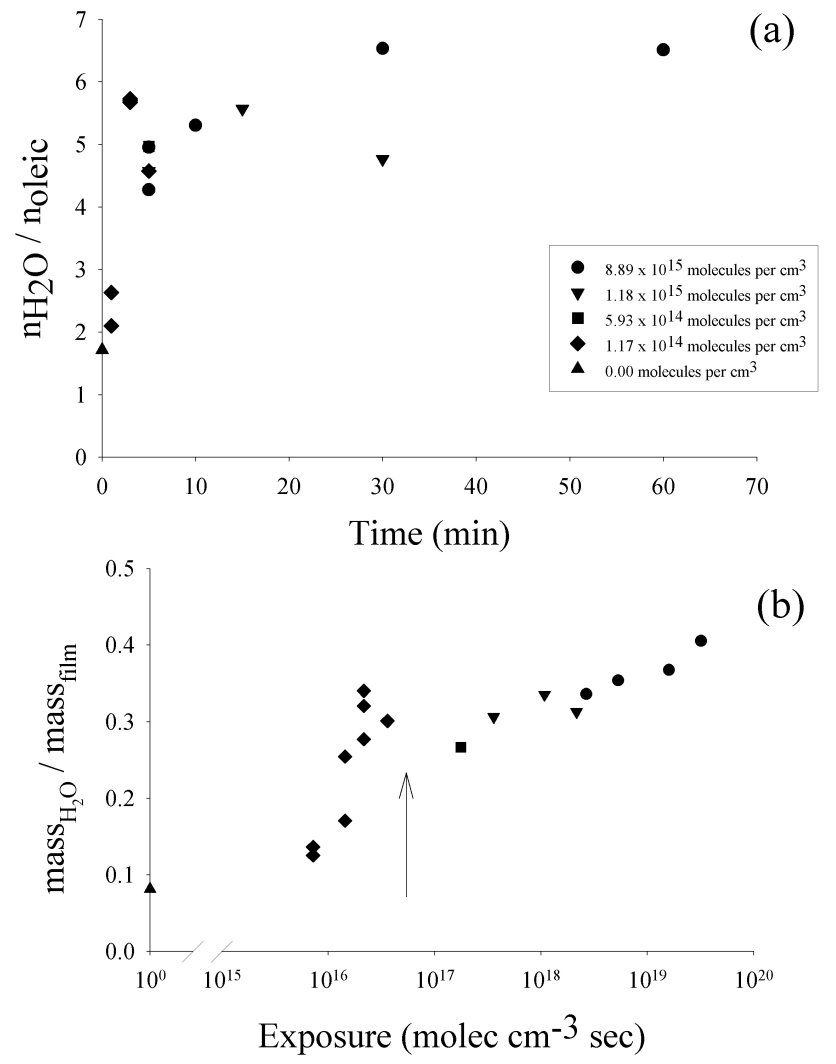

Fig. 3. (a) Moles of water taken up at $95 \%$ relative humidity per mole of oleic acid, plotted as a function of the ozone exposure time for several different ozone concentrations. (b) Amount of water sorbed (in gram of water per gram of film material) measured at $95 \%$ relative humidity as a function of the exposure to ozone, defined as the ozone concentration times the exposure time. Note the initial rapid rise then slow increase, over several orders of magnitude. The arrow indicates the exposure at which all of the oleic acid could have reacted.

Exposure of oleic acid to ozone gives products indicative of ozone attack at the $\mathrm{C}=\mathrm{C}$ double bond, with nonanal evolved to the gas phase (Moise and Rudich, 2003; Thornberry and Abbatt, 2004 )and several low vapour pressure products remaining in the condensed phase (Moise and Rudich, 2003; Smith et al., 2002; Katrib et al., 2004). Our observation of a mass change in the film and its change in hygroscopic properties imply that a chemical reaction has occurred. Therefore, it seems inappropriate to consider the uptake of water in moles of water per mole of oleic acid, since the amount of oleic acid has decreased. Figure $3 b$ shows the data from Fig. 3a transformed to show the uptake in grams of water per gram of film material remaining after oxidation. The ordinate in this case is the exposure to ozone, given in units of molec $\mathrm{cm}^{-3} \mathrm{sec}$. The arrow indicates the value of the exposure at which, assuming a reactive uptake coefficient of $10^{-3}$, all of the oleic acid present in the film is expected to have reacted with ozone. The position of the arrow 
strongly suggests that water uptake increases monotonically with ozone exposure until all the oleic acid has reacted, after which the condensed phase product(s) react more slowly. Overall, there is an increase by a factor of 3-4 in the mass of water sorbed by the processed oleic acid film over that sorbed by the oleic acid originally present.

\subsection{Infrared spectra of processed films}

To investigate the chemical changes in the film which give rise to the increased water uptake, we measured infrared spectra of films before and after processing by ozone. Figure 4a shows a spectrum of the neat oleic acid film. The unprocessed film yields a spectrum with features essentially identical to those given in the NIST database (Coblentz Society, 2003) and the Aldrich atlas (Pouchert, 1981). Figure $4 \mathrm{~b}$ displays the spectrum measured after an exposure to ozone of approximately $5 \times 10^{17} \mathrm{molec} \mathrm{cm}^{-3} \mathrm{sec}$. Dramatic differences are seen around $3400 \mathrm{~cm}^{-1}, 2300 \mathrm{~cm}^{-1}$ and $1400 \mathrm{~cm}^{-1}$, with obvious changes as well in the olefinic bands near 930 and $720 \mathrm{~cm}^{-1}$ and a small blue shift in the carbonyl $\mathrm{CO}$ stretch band near $1700 \mathrm{~cm}^{-1}$. The olefinic bands decrease in intensity relative to the $\mathrm{C}=\mathrm{O}$ stretch, consistent with oxidative attack at these sites. Broad absorptions in the $3400 \mathrm{~cm}^{-1}$ and $2300 \mathrm{~cm}^{-1}$ spectral regions probably correspond to $\mathrm{OH}$ stretching transitions of polymeric species and associated carboxylic acids, respectively (Colthup et al., 1975; Simon and Clerc, 1971). Polyacidic, highly oxidized humic-like substances are found in significant quantities in atmospheric aerosols, especially those influenced by biomass burning (Kiss et al., 2003; Mayol-Bracero et al., 2003). Interestingly, the broad spectral features in the $\mathrm{OH}$ stretching region somewhat resemble those observed for humic acids, (Simpson, 1999) consistent with significant polymerization occurring in the oxidized samples.

Until very recently, the ozonation of oleic acid was thought to yield significant amounts of condensed phase azelaic acid, which is co-produced with the gas phase nonanal product, observed by many workers. Figure $4 \mathrm{c}$ shows the infrared spectrum of an azelaic acid film, measured in the same way as the oleic acid films. It is clear that the spectrum seen in Fig. $4 \mathrm{~b}$ is not that of azelaic acid, but of a substance or mixture of substances which is much more highly oxidized.

\section{Discussion}

The water uptake behaviour of unprocessed oleic acid is interesting. One might have expected only a very small amount of water being sorbed, because of the long hydrophobic chain of the compound. Our earlier work (Demou et al., 2003) did find a very small uptake of water by dodecane, having only about half the hydrophobic chain length of oleic acid, amounting to about 0.05 moles of water per mole of organic. This amount of uptake was similar to that reported for hy-

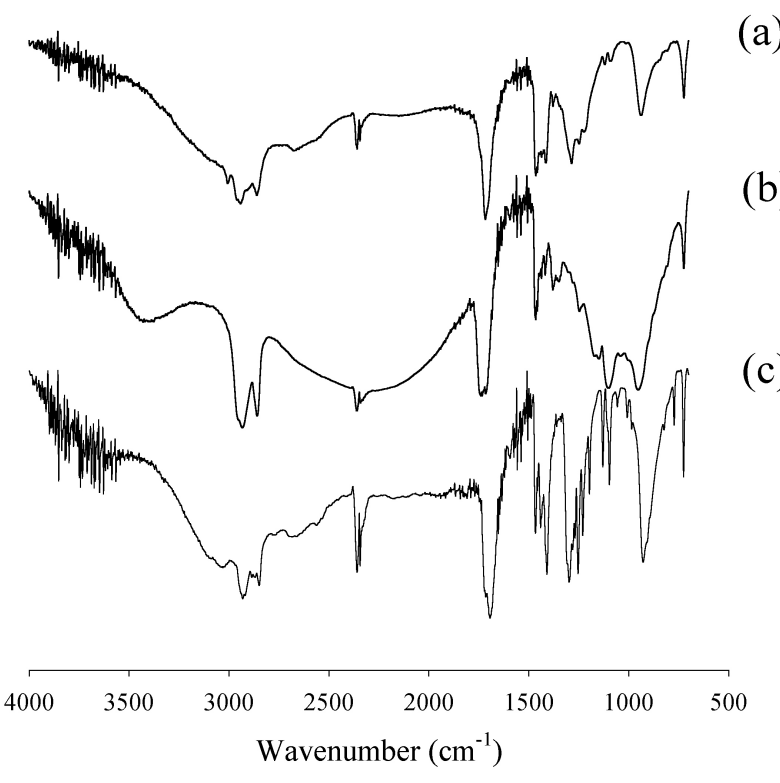

(a)

Fig. 4. (a) Infrared spectrum of a neat oleic acid film. (b) Infrared spectrum of an oleic acid film, processed by expossure to $5 \times 10^{17}$ molec $\mathrm{cm}^{-3} \mathrm{sec}$ of ozone. Note the appearance of very intense $\mathrm{OH}$ stretching transitions near $3400 \mathrm{~cm}^{-1}$ and $2300 \mathrm{~cm}^{-1}$ and the decrease in the bands associated with olefinic molecules in the $700-950 \mathrm{~cm}^{-1}$ region. (c) Infrared spectrum of an azelaic acid film.

drophobic self-assembled monolayers (Rudich et al., 2000). In the latter case, the water uptake was explained as adsorptive, with water condensing on surface defect sites. In the case of oleic acid it might be that the carboxylic acid groups act as condensation sites for water, increasing the propensity for sorption, and thus giving a similar uptake to that seen in octanoic acid.

As expected, we observe an increase in the ability of oleic acid films to sorb water following their exposure to ozone. The enhancement in the water uptake ability increases with increasing ozone exposure, with the rate of increase becoming smaller when the exposure suggests that each oleic acid molecule could have reacted. The infrared spectra of the condensed phase product(s) show a large increase in the concentration of $\mathrm{OH}$ groups, both acidic and alcoholic, consistent with oxidation of the mono-acid to more highly oxidized species. These moeties are capable of entering into strong hydrogen bonded interactions with water, which is the most likely explanation for the increase in water-sorbing ability.

Interestingly, the infrared spectra do not show evidence of azelaic acid being an important condensed phase product of oxidation. The identification of nonanal as a significant gas phase product suggested that azelaic acid should be produced and remain in the condensed phase. Very recently, however, Katrib et al. (2004) have determined that azelaic acid is not a large component of the oxidised condensed phase product. Instead, 9-oxononanoic acid is found 
to be a major ( $>25 \%$ ) product, along with unidentified products of empirical formula $\mathrm{C}_{\mathrm{x}} \mathrm{H}_{\mathrm{y}} \mathrm{O}_{\mathrm{z}}$. They explain the appearance of these latter products by suggesting that the Criegee diradical, which is formed with nonanal when ozone adds across the oleic acid $\mathrm{C}=\mathrm{C}$ double bond, reacts with a neighbouring oleic acid molecule. Free radical polymerization reactions have recently been established to take place in model secondary organic aerosols (Kalberer et al., 2004; Tolocka et al., 2004). Such reactions are almost certainly taking place in our system, as well.

Additionally, Katrib et al. (2004) report an increase in the oxygen:carbon ratio of the film with increasing ozone exposure. This increase in oxidation with increasing exposure is suggested to continue even after all the $\mathrm{C}=\mathrm{C}$ double bonds of oleic acid are (presumed) reacted, perhaps by formation of secondary ozonides or reaction at the carboxylic acid group. An increasing O:C ratio of the film with increasing ozone exposure is implied as well by our infrared spectra, which show the condensed phase becoming richer in $\mathrm{OH}$ groups (and maintaining its concentration of $\mathrm{C}=\mathrm{O}$ groups) with increasing oxidation. The higher degree of oxidation following oxidation was postulated by Katrib et al. (2004) to increase the hygroscopic nature of the condensed phase material as well, a suggestion confirmed by our results.

Recent work by Abbatt and coworkers (Broekhuizen et al., 2004) finds that pure oleic acid particles do not become effective $\mathrm{CCN}$ until they have had high exposure to ozone. At a supersaturation ratio of $0.6 \%$ supersaturation, particles of $180 \mathrm{~nm}$ were found to activate following an ozone exposure of $3 \times 10^{18}$ molec $\mathrm{cm}^{-3} \mathrm{sec}$, considerably greater exposure than required for one reaction per oleic acid molecule. In order to be measured as activated, a particle must increase from its initial diameter to several microns in size. Our results, at relative humidites a bit below saturation, suggest that significant oxidation of the original oleic acid sample must take place in order to increase substantially the amount of water sorbed. We estimate that a $200 \mathrm{~nm}$ diameter particle of pure oleic acid could increase in diameter (at 95\% RH) by $<5 \mathrm{~nm}$; after processing, this growth could increase to about $20 \mathrm{~nm}$. This change suggests that at $\mathrm{RH}>100 \%$, activation could occur for processed particles much more readily than for unprocessed particles. The slow growth in hydrophilicity we observe at exposures above that required to react all the oleic acid, in light of the Broekhuizen et al. (2004) results, suggests that it is the "greater-than-fully processed" oleic acid particles which act as effective CCN.

Notably, particles formed by nebulization of oleic acid/methanol solution are found to activate, even without exposure to ozone (Broekhuizen et al., 2004). This finding is consistent with our observation of very much greater water uptake by films prepared from methanol solution. It is not clear why this should be the case; there may be a condensation reaction occurring, forming an ester, which might be more hygroscopic than the acid. Aternatively, a 3-component (acid-alcohol-water) system could have considerably differ- ent properties than the simple acid-water system, even at very low methanol concentrations. To our knowledge, the phase diagram for this system is unknown.

\section{Conclusions}

We have quantitatively measured the increase in water uptake by films of oleic acid following oxidative processing by ozone. At exposure levels such that all the oleic acid should have reacted, there is an increase by a factor of 3-4 in the amount of water sorbed by the film. The processed films show extensive oxidation, as inferred from infrared spectra which show large enhancements in O-H stretching absorptions. These spectra are consistent as well with a polymeric substance being formed as the condensed phase product of processing.

Acknowledgements. We are grateful to CFCAS and to NSERC for financial support of this work. We thank J. Abbatt, K. Broekhuizen, and Y. Rudich for enlightening discussions on this subject and for providing unpublished work.

Edited by: M. Ammann

\section{References}

Bertram, A. K., Ivanov, A. V., Hunter, M., Molina, L.T., and Molina, M. J.: The reaction probability of $\mathrm{OH}$ on organic surfaces of tropospheric interest, J. Phys. Chem. A, 105, 9415-9421, 2001.

Broekhuizen, K., Thornberry, T., Kumar, P., and Abbatt, J. P. D.: Formation of Cloud Condensation Nuclei by Oxidative Processing: Unsaturated Fatty Acids, J. Geophys. Res., in press, 2004.

Coblentz Society, Inc.: Evaluated Infrared Reference Spectra, in: NIST Chemistry WebBook, NIST Standard Reference Database Number 69, edited by: Linstrom, P. J. and Mallard, W. G., March 2003, National Institute of Standards and Technology, Gaithersburg MD, 20899, http://webbook.nist.gov, 2003.

Colthup, N. B., Daly, L. H., and Wiberly, S. E.: Introduction to infrared and Raman spectroscopy, 2nd Ed. Academic Press, New York, 1975.

De Gouw, J. A. and Lovejoy, E. R.: Reactive uptake of ozone by liquid organic compunds, Geophys. Res. Lett., 25, 931-934, 1998.

Demou, E., Visram, H., Donaldson, D. J., and Makar, P. A.: Uptake of water by organic films: the dependence on the film oxidation state, Atmos. Environ., 37, 3529-3537, 2003.

Eliason, T. L., Gilman, J. B., and Vaida, V.: Oxidation of organic films relevant to atmospheric aerosols, Atmos. Environ., 38, 1367-1378, 2004.

Eliason, T. L., Aloisio, S., Donaldson, D. J., Cziczo, D. J., and Vaida, V.: Processing of unsaturated organic acid films and aerosols by ozone, Atmos. Environ., 37, 2207-2219, 2003.

Ellison, G. B., Tuck, A. F., and Vaida, V.: Atmospheric processing of organic aerosols, J. Geophys. Res., 104, 11 633-11 641, 1999.

Finlayson-Pitts, B. J. and Pitts, J. J. N.: Chemistry of the Upper and Lower Atmosphere, Academic Press, San Diego, 2000. 
Hemming, B. L. and Seinfeld, J. H.: On the hygroscopic behaviour of atmospheric organic aerosols, Industrial and Engineering Chemistry Research, 40, 4162-4171, 2001.

Kalberer, M., Paulsen, D., Sax, M., Steinbacher, M., Dommen, J., Prevot, A. S. H., Fisseha, R., Weingartner, E., Frankevich, V., Zenobi, R., and Baltensperger, U.: Identification of polymers as major components of atmospheric organic aerosols, Science, 303, 1659-1662 2004.

Katrib, Y., Martin, S. T., Hung, H.-M., Rudich, Y., Zhang, H., Slowik, J. G., Davidovits, P., Jayne, J. T., and Worsnop, D. R.: Products and mechanisms of ozone reactions with oleic acid for aerosol particles having core-shell morphologies, J. Phys. Chem. A, in press, 2004.

Kiss, G., Tombacz, E., Varga, B., Alsberg, T., and Persson, L.: Estimation of the average molecular weight of humic-like substances isolated from fine atmospheric aerosol, Atmos. Environ., 37, 3783-3794, 2003.

Matsumoto, K., Tanaka, H., Nagao, I., and Ishizaka, Y.: Contribution of particulate sulfate and organic carbon to cloud condensation nuclei in the marine atmosphere, Geophys. Res. Lett., 24, 655-658, 1997.

Mayol-Bracero, O. L., Guyon, P., Graham, B., Roberts, G., Andreae, M. O., Decesari, S., Facchini, M. C., Fuzzi, S., and Artaxo, P.: Water-soluble organic compounds in biomass burning aerosols over Amazonia - 2. Apportionment of the chemical composition and importance of the polyacidic fraction, J. Geophys. Res., 107, art. no. 8091, 2002.

Middlebrook, A. M., Murphy, D. M., and Thomson, D. S.: Observations of organic material in individual marine particles at Cape Grim during the First Aerosol Characterization Experiment (ACE 1), J. Geophys. Res., 103, 16475-16 483, 1998.

Moise, T. and Rudich, Y.: Reactive uptake of ozone by proxies for organic aerosols: surface versus bulk processes, J. Geophys. Res., 105, 14 667-14 676, 2000.

Moise, T. and Rudich, Y.: Reactive uptake of ozone by aerosolassociated unsaturate fatty acids: kinetics, mechanism and products, J. Phys. Chem. A, 106, 6469-6476, 2003.

Morris, J. W., Davidocits, P., Jayne, J. T., Jimenez, J. L., Shi, Q., Kolb, C. E., Worsnop, D. R., Barney, W. S., and Cass, G.: Kinetics of submicron oleic acid aerosols with ozone: a novel aerosol mass spectrometric technique, Geophys. Res. Lett., 29, art. no. 1357, 2002.

Murphy, D. M., Thomson, D. S., and Mahoney, T. M. J.: In situ measurements of organics, meteoritic material, mercury, and other elements in aerosols at 5 to 19 kilometers, Science, 282, 1664-1669, 1998a.

Murphy, D. M., Thomson, D. S., Middlebrook, A. M., and Schein, M. E.: In situ single-particle characterization at Cape Grim, J. Geophys. Res., 103, (D13), 16485-16491, 1998 b.

Novakov, T., Corrigan, C. E., Penner, J. E., Chuang, C. C., Rosario, O., and Bracero, O. L. M.: Organic aerosols in the Caribbean trade winds: A natural source?, J. Geophys. Res., 102, $21307-$ $21313,1997 \mathrm{a}$.
Novakov, T., Hegg, D. A., and Hobbs, P. V.: Airborne measurements of carbonaceous aerosols on the East Coast of the United States, J. Geophys. Res., 102, 30 023-30 030, 1997 b.

Novakov, T. and Penner, J. E.: Large Contribution of Organic Aerosols to Cloud-Condensation- Nuclei Concentrations, Nature, 365, 823-826, 1993.

Pouchert, C. J.: Aldritch library of infrared spectra, 3rd Ed. Aldrich Inc., Milwaukee, 1981.

Rodahl, M. and Kasemo, B.: On the measurement of thin liquid overlayers with the quartz-crystal microbalance, Sensors and Actuators A, 54, 448-456 1996.

Rudich, Y., Benjamin, I., Naaman, R., Thomas, E., Trakhtenberg, S., and Ussyshkin, R.: Wetting of hydrophobic organic surfaces and its implications to organic aerosols in the atmosphere, J. Phys. Chem. A, 104, 5238-5245, 2000.

Rudich, Y.: Laboratory perspectives on the chemical transformations of organic matter in atmospheric particles, Chem. Rev., 103, 5097-5124 2003.

Saxena, P., Hildemann, L. M., McMurry, P. H., and Seinfeld, J. H.: Organics alter hygroscopic behavior of atmospheric particles, J. Geophys. Res. D, 100, 18 755-18 770, 1995.

Saxena , P. and Hildemann, L. M.: Water absorption by organics: survey of laboratory evidence and evaluation of UNIFAC for estimating water activity, Environmental Science and Technology 31, 3318-3324, 1997.

Schauer, J. J., Rogge, W. F., Hildemann, L. M., Mazurek, M. A., Cass, G. R., and Simoneit, B. R. T.: Source apportionment of airborne particulate matter using organic compounds as tracers, Atmos. Environ., 30, 3837-3855, 1996.

Simon, W. and Clerc, T.: Structural analysis of organic compounds by spectroscopic methods, Macdonald and Co. London, 1971.

Simpson, A. J.: The identification of structures from podzols under differing vegetation, $\mathrm{PhD}$ thesis, University of Birmingham, 1999.

Smith, G. D., Woods, E., DeForest, C. L., Baer, T., and Miller, R. R.: Reactive uptake of ozone by oleic acid aerosol particles: applications of single-particle mass spectrometry to heterogeneous reaction kinetics, J. Phys. Chem. A, 106, 8085-8095, 2002.

Thomas, E. R., Frost, G. J., and Rudich, Y.: Reactive uptake of ozone by proxies for organic aerosols: surface-bound and gasphase products, J. Geophys. Res. 106, 3045-3056, 2001.

Thornberry, T. and Abbatt, J. P. D.: Heterogeneous reaction of ozone with liquid unsaturated fatty acids: detailed kinetics and gas-phase product studies, Phys. Chem. Chem. Phys., 6, 84-93, 2004.

Tolocka, M. P., Jang, M., Ginter, J. M., Cox, F. J., Kamens, R. M., and Johnston M. V.: Formation of oligomers in secondary organic aerosol, Environ. Sci. Technol., 38, 1428-1434 2004.

Tsionsky, V. and Gileadi, E.: Use of the quartz crystal microbalance for the study of adsorption from the gas phase, Langmuir, 10, 2830-28351994. 